Artigo original

Hegemonia - Revista Eletrônica de Relações Internacionais do Centro

Universitário Unieuro

ISSN: $1809-1261$

UNIEURO, Brasília, número 13, 2014, pp. 4-23.

Recebido em: $21 / 3 / 2014$

Avaliado em:4/4/2014

Aprovado em: 8/5/2014

\title{
Crise econômica global: Crise as usual ou oportunidade?
}

ANTONI, Giorgio de ${ }^{1}$

Resumo: A crise econômica global não é apenas econômica, mas também social e ambiental. Ao contrário da visão reducionista que privilegia o funcionamento do mercado e considera a sociedade e o meio ambiente como subsistemas do mesmo, o artigo propõe interpretar o atual momento histórico como uma "crise do sistema".

Palavras-chave: Crise econômica; Sociedade; Meio ambiente.

Abstract: The global financial crisis is not simply financial. It is also a social and environmental crisis. This article opposes the reductionist perspective, which gives pride of place to market forces, and instead proposes an interpretation of this moment of history as a "crisis of the system".

Key Words : Financial crisis; Society; Environment.

Introdução

Embora dentro do sistema econômico a crise constitua um momento recorrente, endógeno na forma de acumulação do capital como apontam os ciclos de Kondatrieff, é a partir dos anos 70 que os aspectos característicos dos momentos de depressão (contração significativa da produção, queda dos preços, cadeia de falências, aumento do desemprego e redução do salário) começaram a se apresentar sempre

1 Doutor em Estudos do Desenvolvimento. 
Artigo original

Hegemonia - Revista Eletrônica de Relações Internacionais do Centro Universitário Unieuro

ISSN: $1809-1261$

UNIEURO, Brasília, número 13, 2014, pp. 4-23.

mais frequentemente. A atual grande depressão que está afetando a economia global, cujo inicio é geralmente marcado no ano 2008 com a quebra do Banco Lehman Brothers, é mais uma etapa desse processo de instabilidade na economia de mercado. Com efeito, a partir dos anos 70, o ciclo das crises bancárias regionais apresenta um ritmo quase decenal: a crise da dívida americana nos anos 80; a das "Economias de Transição" na década de 90; a crise econômica mexicana (Tequila crisis) em 1994 e a asiática em 1997; e, em 2008, o pior momento da economia mundial depois da Grande Depressão do 1929, como o definiu Christine Lagarde, a atual diretora do Fundo Monetário Internacional (2012).

A amplidão e a intensidade dessa última crise não é determinada apenas pelas perdas financeiras, $\$ 34,4$ trilhões (CK Liu, 2010)', mas principalmente por ter atingido pela primeira vez, desde os anos 70, o centro da economia e da finança internacional. A consequência natural desse fenômeno foi a contração da economia global, inclusive da América Latina e do Brasil, embora em graus diferentes. Na América Latina os efeitos negativos da crise internacional afetaram particularmente as exportações que no final do 2008 chegaram a uma queda de 30\% (Ocampo, 2009).

Apesar de o Brasil ter sido preservado dos graves problemas que atingem as economias ocidentais, a desaceleração do PIB mundial (de $4,9 \%$ em 2007 a $3 \%$ em 2013) se refletiu também no PIB brasileiro que passou das metas previstas de 4\% a 1,5\%, em 2012 (IMF, 2012), e em 2013, a 2,5\% (IMF, 2013) marcando assim a mais modesta recuperação entre os países emergentes. A opinião dos especialistas é que "the 
Artigo original

Hegemonia - Revista Eletrônica de Relações Internacionais do Centro Universitário Unieuro

ISSN: 1809-1261

UNIEURO, Brasília, número 13, 2014, pp. 4-23.

aftermaths of severe financial crises are characterized by long, deep recessions (...). And the bottom is much deeper." (Reinhart \& Rogoff, 2012). A dimensão global da economia globaliza os efeitos da crise e, haja vista o tempo que vai precisar para sua recuperação, o mundo terá que assumir como normalidade essa "anomalia". Todavia, numa economia de mercado que constitui a "fonte e a matriz" (Polany, 1982, p. 21) do sistema político e social existente, é evidente que a crise financeira acirra certos problemas e induz a uma reflexão crítica sobre a mesma. Entre os temas mais gerais e sensíveis instigados pela depressão econômica três abrangem de forma específica a dimensão internacional: o questionamento do papel dominante da economia, as repercussões sociais da crise e a perspectiva ameaçadora do meio ambiente.

As questões econômicas, sociais e ambientais levantadas pela crise

Apesar do caráter recorrente e quase necessárioii das crises dentro do sistema de mercado elas aparecem sempre de forma imprevisível e abrupta, como um evento da natureza. A maioria dos estudos econômicos é elaborada a partir do axioma da eficiência do mercado, com o conforto do mesmo pai da ciência econômica, Adam Smith. É apenas nos momentos de turbulência financeira que são exumados os, assim chamados, economistas da crise (Roubini e Mihm, 2010) para melhor entender a etiologia e o funcionamento desse fenômeno insólito. Hyman Minsky é, sem dúvida, o mais evocado desde o começo da 
Artigo original

Hegemonia - Revista Eletrônica de Relações Internacionais do Centro Universitário Unieuro

ISSN: $1809-1261$

UNIEURO, Brasília, número 13, 2014, pp. 4-23.

quebra do Banco Lehman Brothers por ter previsto e anunciado o colapso antes de acontecer (faleceu em 1996), ao ponto que os cientistas em matéria definem a atual conjuntura econômica como "the Minsky moment".

A tese fundamental de Minsky é que a necessidade de um quadro estável exigida para o funcionamento e desenvolvimento dos mercados financeiros leva, a longo prazo, ao seu contrário por causa do impulso humano que age sobre os algoritmos econômicos (1986). Essa influência humana acerca dos cálculos matemáticos faz que as economias capitalistas evoluam de modo inevitável do financiamento conservador para a especulação irresponsável (o esquema Ponzi). Na opinião de Minsky, o grande erro foi não levar em conta, como teria precisado, a inovação financeira. A uma expansão técnica (informática) e política (neoliberalismo) dos anos 80 não correspondeu uma adequada regulamentação da atividade bancária e das operações financeiras (Stiglitz, 2008; Krugman, 2012).

De fato, a capacidade auto-reguladora do mercado fica profundamente questionada haja vista o bailout dos governos em prol dos bancos, principais responsáveis pela crise, às custas das sociedades nacionais. A situação americana é mais uma vez exemplar pela ajuda bancada em favor das instituições financeiras em apuro: dos \$13,3 trilhões custeados por Washington para superar a crise, $\$ 11,490$ foram para as instituições de Wall Street e \$1,823 em proveito dos cidadãos americanos (Prins, 2010). Como bem observa Kurz (1992), que desde 1991 previu a crise dos países capitalistas e a passagem da mesma crise 
Artigo original

Hegemonia - Revista Eletrônica de Relações Internacionais do Centro Universitário Unieuro

ISSN: 1809-1261

UNIEURO, Brasília, número 13, 2014, pp. 4-23.

da periferia ao centro, a concorrência pela mais-valia, que tornou possível o desenvolvimento do capital, está se voltando contra o trabalho iii provocando o desemprego e tornando a ocupação uma simples mercadoria considerada unicamente pelo benefício econômico que acarreta.

Depois dos anos 70, a lógica inspiradora do mercado, a maximização do lucro, levou o mercado financeiro a ocupar papel central na economia mundial aumentando sempre mais a fratura entre a economia real e a indústria das transações financeiras internacionais. Essa última, em 2010, alcançou um volume global 67,4 vezes maior que o PIB mundial, enquanto em 1990 era "apenas" 15,3 (Schulmeister, 2011, p. 13). O resultado foi a progressiva diminuição da acumulação do capital produtivo em prol do capital financeiro mais rentável por meio de transações sempre mais sofisticadas e arriscadas, das quais a bolha imobiliária nos Estados Unidos é o ponto final.

Fatos menos notórios e mais alarmantes poderiam revelar disfunções incorporadas pelo sistema financeiro de grande valor premonitório, como, por exemplo, a soma de dinheiro depositado ilegalmente nos vários paraísos fiscais do planeta que monta a 21 trilhões de dólares, correspondentes ao PIB dos Estados Unidos e do Japão juntos, longe das taxas e do cálculo da riqueza no mundo (Shaxson et al., 2012); ou o uso do dinheiro obtido com o tráfico de droga no resgate dos bancos na crise global financeiraiv. Tudo aponta para uma disfunção estrutural no sistema econômico que parece exigir 
Artigo original

Hegemonia - Revista Eletrônica de Relações Internacionais do Centro Universitário Unieuro

ISSN: $1809-1261$

UNIEURO, Brasília, número 13, 2014, pp. 4-23.

uma mudança adequada, "uma mão visível" onde as regras e o controle do mercado sejam mais orientados à realidade social.

De fato, a recaída dos efeitos da crise econômica sobre a sociedade tem como consequência a aplicação de medidas draconianas que visam garantir a produção e o consumo em um momento de desaceleração por meio dos "sacrifícios" dos cidadãos, levados, em nome do trabalho, a padrões de vida que sempre mais sacrificam dimensões existenciais profundas da condição humana. A lógica que impõe um custo humano ao progresso não é uma novidade. Desde o aparecimento da revolução industrial a sociedade foi compelida a uma profunda transformação: "Ao lugar de ser a economia a se encaixar nas relações sociais, são as relações sociais a ser encaixadas no sistema econômico" (Polany, 1982, p. 88). Essa operação dramática e violenta que acompanhará o progressivo desenvolvimento do ocidente foi bem e minuciosamente descrita por Lewis Mumford (1958; 1992), e Hobsbawm verá nessa pressão do poder econômico aliado com o estado moderno a causa das inúmeras revoluções desencadeadas no arco de tempo que vai desde 1789 a 1848 (1969).

A euforia desenvolvimentista do tempo presente, apesar das crises, joga facilmente no esquecimento esse processo forçado. Todos os momentos de "destruição criadora" que caracterizaram a marcha do capitalismo provocaram mais riqueza e mais tecnologia, e, no mesmo tempo, uma redução dos espaços vitais ${ }^{\vee}$. A esse respeito, o paradoxo de Easterlin (1974) é emblemático: o estudo, tomando em consideração o 
Artigo original

Hegemonia - Revista Eletrônica de Relações Internacionais do Centro Universitário Unieuro

ISSN: $1809-1261$

UNIEURO, Brasília, número 13, 2014, pp. 4-23.

espaço de tempo que vai de 1946 até 1970, nos Estados Unidos, chega à conclusão que não existe correlação entre o aumento da renda e a satisfação com a própria vida. Ao contrário, a pesquisa demonstra que o grau de satisfação do americano médio vai decrescendo à medida que o poder aquisitivo aumenta, atingindo o nível mais baixo do Ocidente. Se tal é o resultado de um período histórico especial relativamente à rapidez e ao nível de desenvolvimento alcançado, o momento da crise irá facilmente exacerbar a insatisfação dos tempos "normais". O fato é que as pressões aplicadas para salvar a economia, apelando-se à urgência da situação, entram muitas vezes em choque, abertamente ou sub-repticiamente, com algumas conquistas sociais obtidas no passado.

O caso da Europa na conjuntura econômica atual é significativo. A crise, em nome do estado de urgência que ocasionou, justificou a tomada de medidas ásperas por parte das instituições econômicas e políticas europeias em resposta ao andamento do mercado internacional sem uma consulta democrática das populações envolvidas e da sua participação. A JP Morgan, um dos maiores bancos do mundo, no dia 28 de maio de 2013 publicou um relatório no qual explicava sua interpretação da contração econômica internacional. A crise, de acordo com essa agência, não seria apenas econômica, mas também política: as Constituições de muitos países, redigidas logo depois da guerra numa perspectiva antifascista, foram influenciadas por uma ideologia socialista que, entre outros, defende os direitos do trabalhador, procura construir o consenso político, e dá o direito de protestar frente a qualquer mudança do status quo (p. 12). Conforme a análise da JP Morgan, uma 
Artigo original

Hegemonia - Revista Eletrônica de Relações Internacionais do Centro Universitário Unieuro

ISSN: $1809-1261$

UNIEURO, Brasília, número 13, 2014, pp. 4-23.

resposta rápida e eficaz precisa de uma intervenção por parte de um poder forte em condição de agir sem passar pelo complexo e demorado processo democrático.

O relatório Ruskin, publicado uns meses depois, em novembro, demonstrava que o diagnóstico do banco americano encontrava uma comprovação na estratégia da "guerra à democracia" (Ahmed, 2013) em grande escala travada pelas corporações econômicas internacionais contra as organizações nonprofit, a saber, as formas democráticas de intervenção da sociedade civil (2013). Os dois episódios revelam a contrariedade do mercado diante do direito dos povos de ser protagonistas da própria história, como muitas constituições proclamam, e apontam nitidamente para onde sopra o Espirito do Tempo (Spinelli, 2013) em período de crise econômica: o momento ideal para a incubação de todas as formas de extremismo que estão se alastrando pela Europa inteira (ECRI, 2012) e além da Europa.

Naturalmente, essa tendência do mercado e das instituições políticas a centralizar o poder para uma solução rápida do problema tem sido alvo de críticas profundas por parte dos filósofos e dos cientistas sociais mais conceituados. Entre eles, Jung Habermas que questiona a orientação dominante do mercado e convida a trabalhar para uma união política na qual a tecnocracia esteja a serviço da democracia (2013); enquanto Ulrick Beck propõe um novo contrato social a nível europeu para fugir da tentação econômica de verticalizar o poder (2013). O conflito europeu entre mercado e participação democrática, agravado pela crise, considerado no contexto brasileiro apresenta-se de forma 
Artigo original

Hegemonia - Revista Eletrônica de Relações Internacionais do Centro Universitário Unieuro

ISSN: $1809-1261$

UNIEURO, Brasília, número 13, 2014, pp. 4-23.

diferente seja por causa da boa performance econômica do Brasil, seja em consequência da história das relações sociopolítico econômicas do país.

Todavia, o ritmo crescente do desenvolvimento econômico do Brasil, configurado dentro das leis do mercado global, embora economicamente em boa saúde, não tem adequadamente protegido alguns direitos básicos da população, entre os quais a instrução, a saúde, o transporte e a violência: temas que inspiram as manifestações populares e revelam uma forte insatisfação com respeito às politicas públicas. Mas é principalmente na situação de crise econômica que o mercado perde seu aspecto sedutor e ostenta sua cara coercitiva, fria e tirânica. Nesse momento, a sociedade se encontra a decidir entre uma hetero-regulação imposta pelo sistema de mercado, integrada por meio do consenso em tempos normais, e a auto-regulação social impulsionada pelo mundo vital (Gorz, 1989, p. 33), do qual o meio ambiente faz parte.

Ao contrário da separação entre o humano e a naturezavi proclamada pela modernidade, os dois elementos fazem parte de uma única realidade (Bateson, 2000, p. 496): a sorte de um está intimamente ligada à sorte do outro. Por isso talvez a questão ambiental seja o aspecto mais dramático do que Spengler chama de a "Decadência do Ocidente" (1978). O que hoje em dia torna dramática a relação dos seres humanos com o próprio habitat é o número incalculável de informações que cientificam da grave situação na qual o planeta se encontra e a inércia quase total que caracteriza o desenvolvimento 
Artigo original

Hegemonia - Revista Eletrônica de Relações Internacionais do Centro Universitário Unieuro

ISSN: $1809-1261$

UNIEURO, Brasília, número 13, 2014, pp. 4-23.

socioeconômico e político do mundo a respeito desse drama anunciado. Parafraseando a expressão de Hardin podemos falar de uma "tragédia da mudança climática" como o ponto mais alto e mais representativo dos problemas ambientais. As recentes intervenções do Painel Intergovernamental sobre Mudanças Climáticas (IPCC, em inglês) reforçam declarações anteriores a respeito da influência determinante da causa antropogênica no aquecimento do clima e tiram todas as dúvidas exibidas pelos sépticos da mudança climática: "It is extremely likely that human influence has been the dominant cause of the observed warming since the mid-20th century (2013, p. 15). Na linguagem do IPCC, extremely likely corresponde a $95 \%$ de certeza sobre a responsabilidade humana pelo aquecimento globalvii.

Segundo Stocker, um cientista do Painel, a partir dos anos 1850 o desenvolvimento industrial produziu um aumento de calor no planeta correspondente a 1 grau Celsius (Schiermeier, 2013). Na publicação do $5^{\circ}$ relatório sobre a mudança climática, O IPCC, a fim de não ultrapassar os dois graus Celsius concordados em Copenhague (2009) viii, pela primeira vez colocou um limite nas emissões de carbono igual a um trilhão de toneladas. Como o processo de acumulação é irreversível e fica na atmosfera por séculos, cada tonelada de carbono lançada na atmosfera cria impactos a longo prazo imprevisíveis (Pearce, 2013).

Segundo o cálculo de pesquisadores do departamento de física da Universidade de Oxford até agora teríamos alcançado os 575 bilhões de toneladas: guardando o mesmo trend nas emissões durante os próximos 20 anos, esgotaríamos o limite de um trilhão de toneladas sábado 25 de 
Artigo original

Hegemonia - Revista Eletrônica de Relações Internacionais do Centro Universitário Unieuro

ISSN: $1809-1261$

UNIEURO, Brasília, número 13, 2014, pp. 4-23.

novembro de 2040ix; embora as previsões humanas, por quanto justificadas pelos números, possam revelar surpresas ou por excesso ou, pior, por defeito. Mas, sem aguardar 2040, a situação atual pode ser definida crítica pelo fato de que, pela primeira vez na história, foram detectadas 400 partes por milhão (ppm) de dióxido de carbono na atmosfera, superando assim o limite de 350ppm.

Um recorde que recoloca o planeta nas condições parecidas às do Médio Plioceno ( 3 milhões de anos atrás), o período que antecedeu as atuais configurações da terra, com suas relativas consequências ${ }^{\times}$. A International Energy Agency (IEA), no seu World Energy Outlook 2013 informa que na situação atual, com as medidas ambientais tomadas pelos países e pela comunidade internacional, as emissões de carbono estão destinadas a aumentar 20\% até 2035 com elevação da temperatura a 3,6 graus Celsius. Os "eventos extremos", assim definidos pelo IPCC, irão crescendo em frequência e tamanho. O grito de desespero lançado por Naderev Saño, representante das Filipinas na comissão da ONU sobre o clima, em Varsóvia, seguido por um jejum de protesto para lembrar as inúmeras vítimas da mudança climática e provocar decisões significativas e eficazes no âmbito da COP19, não deu muitos resultados (2013).

A mesma conquista do Warsaw International Mechanism, criado para socorrer as populações afetadas pelos eventos extremos causados pela alteração do clima, tem um sabor amargo: a comunidade internacional prefere bancar a ajuda em lugar de operar mudanças adequadas no seu aparato econômico-industrial existente. Mais uma 
Artigo original

Hegemonia - Revista Eletrônica de Relações Internacionais do Centro Universitário Unieuro

ISSN: $1809-1261$

UNIEURO, Brasília, número 13, 2014, pp. 4-23.

vez, a crise global evidencia um problema especifico e se torna contemporaneamente o pretexto para a manutenção do status quo. Qualquer análise empreendida para explicar a inércia das negociações sobre o meio ambiente chegará a se deparar com um problema fundamental bem enunciado por Vandana Shiva: enquanto o desenvolvimento tem como axioma incontestável a ideologia do crescimento ilimitado, a questão ecológica traz consigo necessariamente a perspectiva do crescimento limitado (1992). A passagem da primazia da natureza à primazia do mercado, ocorrida com a modernidade, colocou o meio ambiente na posição de subsistema da economia; embora, como bem observa Passet, os elementos da esfera econômica pertençam à biosfera e dependam de suas leis, ao passo que todos os elementos da biosfera não pertencem ao econômico, nem se sujeitam às suas normas (1979, p. 9).

Nesses últimos anos de "rebelião" da natureza a um papel subalterno, algumas iniciativas, a nível institucional e acadêmico têm procurado prestar certa atenção às consequências devastadoras do crescimento. A proposta por uma Economia Verde, lançada pelo Programa das Nações Unidas para o Meio Ambiente (PNUMA) em 2008, e entre os temas centrais de Rio+20, visa elevar o "human well being and social equity, while significantly reducing environmental risks and ecological scarcities" (UNEP, 2010, p. 5). E é nesse contexto que foi resgatado o conceito chave do Decoupling ${ }^{\text {xi }}$ cujo objetivo é a desmaterialização da atividade econômica, quebrando o nexo entre 
Artigo original

Hegemonia - Revista Eletrônica de Relações Internacionais do Centro Universitário Unieuro

ISSN: $1809-1261$

UNIEURO, Brasília, número 13, 2014, pp. 4-23.

crescimento e consequente aumento da exploração dos recursos naturais (UNEP, 2011, p. 4).

Contudo, as orientações institucionais tomam em consideração o problema ecológico sem questionar a necessidade do desenvolvimento econômico contínuo imposta pelo atual sistema econômico. Alguns pesquisadores, convencidos de que o crescimento ilimitado tem um aspecto irracional, estão procurando quebrar esse tabu invocando a intuição de Stuart Mill sobre o steady state (Daly, 1977; 1996; Daly and Townsend, 1996), um tempo no qual à progressão econômica se deveria privilegiar a distribuição da riqueza acumulada. Outros ainda propõem o decrescimento (degrowth) (Latouche, 2010; Bonaiuti, 2011) como forma de ralentar a produção e o consumo com o propósito de melhorar o bem estar social e de elevar as condições ecológicas e de igualdade no planeta. Embora as instituições econômicas e políticas estejam unicamente orientadas ao crescimento ilimitado, a crise pode permitir um confronto com essas ideias críticas e ocasionar uma relação diferente com o meio ambiente.

Conclusão

Os três questionamentos aqui rapidamente apresentados sugerem a necessidade de uma visão abrangente da crise econômica, não reducionista. O fato de isolar o problema do contexto, conforme o método analítico clássico que está à base da especializaçâo, prejudica a 
Artigo original

Hegemonia - Revista Eletrônica de Relações Internacionais do Centro Universitário Unieuro

ISSN: 1809-1261

UNIEURO, Brasília, número 13, 2014, pp. 4-23.

compreensão do mesmo problema. A crise não é apenas econômica. Considerando a amplitude e a sincronia dos acontecimentos que abalam o mundo contemporâneo é possível falar de crise do "sistema", entendendo com essa palavra a complexidade, a interligação e a finalidade que caracterizam o projeto civilizacional da época atual. Múltiplas crises que vão da insegurança socioeconômica, do desemprego, ao clima, à biodiversidade e à estrutura financeira global estão questionando profundamente o modelo ocidental baseado na acumulação do capital.

Uma abordagem sistémica ${ }^{\text {xii }}$ vai além da análise das diferentes partes que compõem a realidade universal e fica interessada particularmente pela sinergia produzida por meio das interconexões ${ }^{\text {xiii. }}$ Do ponto de vista etimológico, crise traz a própria origem da palavra krísis que em grego significa, poder de discernimento, decisão, escolha, ponto de mutação. Assim, falar de crise sistêmica corresponderia a um momento no qual os seres humanos se encontram na situaçao de ter que tomar uma decisão sobre sua forma sócio-histórica de estar no mundo. Esse processo de empowerment da humanidade sobre o próprio destino exige uma relativização do sistema existente que se apresenta na forma de ideologia, definida por Althusser como "...uma representação imaginária da relação imaginária dos indivíduos com sua situação real de existência" (1995, p. 216).

A crise seria entâo uma oportunidade de adequar a imaginação dos indivíduos à nova situação real de existência invocada pelos acontecimentos, "decolonizando o imaginário" (Castoriadis, 1975) e abrindo-o a novas possibilidades, a novas modalidades de inventar a 
Artigo original

Hegemonia - Revista Eletrônica de Relações Internacionais do Centro Universitário Unieuro

ISSN: $1809-1261$

UNIEURO, Brasília, número 13, 2014, pp. 4-23.

própria relação com o mundo. De fato, a conjuntura socioeconômica e ambiental atual pode ser encarada de duas formas diferentes: a primeira considera a crise a partir do reducionismo ideológico destacando o problema principalmente econômico e relegando as outras questões a uma posição marginal.

O slogan da Tatcher "TINA" (there is no alternative), lançado nos anos 80 para justificar as medidas tomadas em defesa da economia, expressa muito bem a preferência incontestável das instituições internacionais relativamente ao funcionamento do mercado sobre o qual a sociedade e o meio ambiente têm que ser configurados. A segunda analisa a conjuntura atual de forma crítica valendo-se do arcabouço teórico desenvolvido pela critical theory nas relações internacionais, por meio da contribuição de vários autores (Sinclair, 1996; Linklater, 2000; Gill, 2000 ), mas particularmente de Robert Cox (1996).

Diferentemente da perspectiva da problem-solving theory que se organiza ao redor de um problema a solucionar evitando perturbar os equilíbrios existentes, a critical theory procura se liberar de um a priori vinculador e condicionante com o propósito de sondar as diferentes possibilidades e alternativas despertadas pelas mudanças continuas que caracterizam a realidade. Na prática, o objetivo dessa abordagem é incluir na análise do problema em questão as instituições e as relações de poder consolidadas, encarregadas de intervir naquela situação específica. A orientação crítica, portanto, interpreta a crise sistémica como um fenômeno revelador onde a criatividade e a iniciativa humanas deveriam prevalecer sobre a ordem constituída, embora reconhecendo a complexidade dos processos de transição e a necessidade dos pequenos 
Artigo original

Hegemonia - Revista Eletrônica de Relações Internacionais do Centro Universitário Unieuro

ISSN: $1809-1261$

UNIEURO, Brasília, número 13, 2014, pp. 4-23.

passos. Trata-se no concreto não apenas de apontar cenários possíveis para traduzir os desafios atuais em respostas construtivas e responsáveis, mas também (e isso é menos frequente) de decifrar e aceitar a estratégia progressiva que se encaminha na direção indicada. A crise econômica global se apresenta como um Jano bifronte. De um lado, uma cara severa, autoritária que impõe mais uma vez sacrifícios, desemprego e restrições democráticas, para superar o momento atual e voltar a crescer "como" antes; do outro, uma cara visionária, consciente e desencantada, que aposta no futuro em resposta às provocações da história.Viver a crise as usual o como oportunidade talvez seja a escolha mais difícil na hora atual. 
i

A soma corresponde ao PIB dos Estados Unidos, da União Europeia e do Japão juntos.

ii

Ver o conceito de destruição criadora em Shumpeter (1961).

iii

“[...] a globalização financeira falhou no objetivo de fomentar a produção global ou o aumento do emprego..." (ILO, 2008).

iv

Cf. http://www.reuters.com/article/2009/01/25/financial-un-drugs-idUSLP65079620090125

$\mathrm{V}$

Sobre esse tema veja-se a obra de Ivan Illich, Vernacular Values (1981).

vi

A natureza é definida por Stuart Mill na sua obraThree essays on religion: what is not human. http://www.earlymoderntexts.com/milless.html

vii

Enquanto em 2001 era o $66 \%$ e em 2007 o $90 \%$.

viii

http://unfccc.int/meetings/copenhagen_dec_2009/meeting/6295.php

ix

http://www.trillionthtonne.org/questions.html

$\mathrm{x}$

http://www.ipcc.ch/publications and data/ar4/wg1/en/ch6s6-3-2.html

$\mathrm{xi}$

A proposta do Decoupling tem que ser atrubuida a Organização para a Cooperação e Desenvolvimento Econômico (OCDE) que em 2001 a lançou pela primeira vez.

xii

Ver Bertalanffy (1968).

xiii

Como na psicologia da gelstat.

\section{Referências bibliográficas}



1995.

ALTHUSSER, L. Sur la reproduction. Paris : Presse Universitaire de France,

AHMED, N. The war on Democracy. The Guardian, 28 november 2013. Disponível em: http://www.theguardian.com/environment/earthinsight/2013/nov/28/war-on-democracy-corporations-spy-profit-activism Acesso em: 28.11.2013.

BATESON, G. The Roots of Ecological Crisis. In: . Steps to an ecology of Mind. The University of Chicago Press, 2000.

BECK, Ulrich. Towards a European spring. Open Democracy, 19 March 2013. Disponível em: http://www.opendemocracy.net/ulrich-beck/towardseuropean-spring Acesso em: 22.11.2013.

BERTALANFFY, L. General System Theory. Foudantions, Development, Applications. New York: Braziller, 1968.

BONAIUTI, M. From Bioeconomics to Degrowth.Georgescu-Roegen's "New Economics" in eight essays. London : Routledge, 2011.

CASTORIADIS, C. L'institution imaginaire de la société. Paris : Editions du Seuil, 1975.

COX, R. Social forces, states, and world orders : beyond international relations theory (1981). In: COX, R. and SINCLAIR, T. J. Approaches to world order. Cambridge University Press, 1996.

CK LIU, H. The crisis of wealth destruction. Asia Times, April 13, 2010. Disponível em: http://atimes.com/atimes/Global Economy/LD13Dj05.html Acesso em: 11.09.2011.

DALY, H. E. Steady-State Economics. The Economics of Biophysical Equilibrium and Moral Growth. San Francisco: W. H Freeman and Company, 1977. . Beyond Growth. Boston: Beacon Press books, 1996.

DALY, H. E. and TOWNSEND, K. N. Valuing the earth: economic, ecology, ethics. Massachusets: Institute of Technology, 1996.

EASTERLIN, R. A. Does Economic Growth Improve the Human Lot? Some Empirical Evidence. In: DAVID, P. A. and REDER, M. W. (eds). Nations and Households in Economic Growth: Essays in Honor of Moses Abramovitz. New York: Academic Press, 1974.

ECRI. Annual Report on ECRI's Activities. Covering the period from 1 January to 31 December 2012. European Commission against Racism and Intolerance. $2012 . \quad$ Disponível em: http://www.coe.int/t/dghl/monitoring/ecri/activities/Annual_Reports/Annual \%20report\%202012.pdf Acesso em: 28.11.2013.

GILL, S. Globalisation, Market Civilisation, and Disciplinary Neoliberalism. In: LINKLATER, A. (ed.) International relations: critical concepts in political science. London: Routledge, 2000. 
GORZ, A. Critique of Economic Reason. London-New York: Verso, 1989.

HABERMAS, J. Democracy, Solidarity and the European Crisis. Lecture delivered on 26 April 2013 in Leuven. 2013. Disponível em: http://www.kuleuven.be/communicatie/evenementen/evenementen/jurgen-

habermas/democracy-solidarity-and-the-european-crisis Acesso em: 24.11.2013.

HOBSBAWN, E. J. L'ère des revolutions. Paris: Fayard, 1969.

ILLICH, I. VernacularValues. 1981. Disponível em: http://www.preservenet.com/theory/Illich/Vernacular.html Acesso em: 30.11.2013.

IMF. World Economic Outlook, October 2012. International Monetary Fund. 2012. Disponível em:

http://www.imf.org/external/pubs/ft/weo/2012/02/pdf/text.pdf

Acesso em: 30.09.2012.

IMF. Regional Economic Outlook Update, Western Hemisphere Department. International Monetary Fund, 11 October 2013. Disponível em: http://www.imf.org/external/pubs/ft/reo/2013/whd/eng/pdf/wreo1013.pdf

Acesso em: 26.11.2013.

IEA. World Energy Outlook 2013. INTERNATIONAL ENERGY AGENCY. Disponível em:

http://www.worldenergyoutlook.org/media/weowebsite/2011/executive summary .pdf

Acessoem: 18.11.2013.

ILO. World of Work. Report 2008. Income Inequalitites in the Age of Financial Globalization. INTERNATIONAL LABOR ORGANIZATION. 2008. Disponível em:

http://www.ilo.org/public/english/bureau/inst/download/world08.pdf

Acesso em: 27.09.2012.

IPCC. Working Group I Contribution to the IPCC Fifth Assessment Report Climate Change 2013: The Physical Science BasisSummary for policymakers. Intergovernmental Panel on Climate Change, 27 September 2013. Disponível em: http://www.climatechange2013.org/images/uploads/WGI AR5 SPM brochure.pdf Acesso em: 28.09.2013.

J.P. MORGAN. The Euro area adjustment: about halfway there. Issuepedia, 28 May 2013. Disponível em: http://issuepedia.org/File:JPM-the-euro-areaadjustment--about-halfway-there.pdf Acesso em: 30.11.2013.

KRUGMAN, P. Why we regulate. The New York Times, 13 may 2012. Disponível em: http://www.nytimes.com/2012/05/14/opinion/krugman-why-weregulate.html?partner $=r s s n y t \& e m c=r s s \& \quad r=0 \quad$ Acesso em: 28.11.2013.

LAGARDE, C. Back to Rio-the Road to a Sustainable Economic Future. InternationalMonetaryFund, June 12, 2012. Disponível em: 
24.09.2013.

LATOUCHE, S. Pour sortir de la société de consommation : Voix et Voies de la décroissance. Paris: LLL, 2010.

LINKLATER, A. International relations: critical concepts in political Science. London: Routledge, 2000.

MINSKY, H. Stabilizing an Unstable Economy. Yale University Press, 1986.

MUMFORD, L. A condição de homem: uma análise dos propósitos e fins do desenvolvimento humano. São Paulo: Ed. Globo, 1958.

. Técnica e Civilización. Madrid: AlianzaUniversidad, 1992.

OCAMPO, J. A. Latin America and the global financial crisis. Cambridge Journal of Economics, n 33, pp. 703-724, 2009. Disponível em:

http://www.perpustakaan.depkeu.go.id/folderjurnal/703.full.pdf

Acesso em: 14.03.2010.

PASSET, R. L'économique et le vivant. Paris : Payot, 1979.

PEARCE, F. The Trillion Ton-Cap: Allocating The World's Carbon Emissions. Yale environment 360, 24 October 2013. Disponível em: http://e360.yale.edu/feature/the trillionton cap allocating the worlds carbon emissions/2703/ Acesso em: 25.10.2013

POLANY, K. La Grande Transformation. Aux origines politiques et économiques de notre temps. Paris : Gallimard, 1982.

KURZ, R. O Colapso da Modernização. Da derrocada do socialismo de caserna à crise da economia mundial. Rio de Janeiro: Ed. Paz e Terra, 1992.

PRINS, N. and UGRIN, K. Bailout Tally Report. January 12, 2010. Disponível em:

http://www.nomiprins.com/storage/bailouttallyoct2011CLEAN\%20NO \%20FORMULAS.pdf

Acesso em: 24.09.2012.

REINHART, C. M. \& ROGOFF, K. S. Five Years After Crisis, No Normal Recovery. Bloomberg, 2April $2012 . \quad$ Disponível em: http://www.bloomberg.com/news/2012-04-02/five-years-after-crisis-no-normalrecovery.html Acesso em: 26.11.2013.

ROUBINI, N. e MIHM, S. A economia das crises. Um curso-relâmpago sobre o futuro do sistema financeiro internacional. Rio de Janeiro: Ed. Intrínseca, 2010.

RUSKIN, G. Spooky Business: Corporate Espionage Against Nonprofit Organizations. Essential Information, November 20, 2013. Disponível em: 
http://www.corporatepolicy.org/spookybusiness.pdf Acesso em: 21.11.2013.

SAÑO, N. Typhoon Haijan: we cannot afford to procrastinate on climate action. The Guardian, 11 November 2013. Disponível em: http://www.theguardian.com/world/2013/nov/11/typhoon-haiyan-philippinesclimate-change Acesso em 11.11.2013.

SCHAXSON, N., CHRISTENSEN, J. and MATHIASON, N. Inequality: You Don't Know the Half of It. Tax Justice Network, 19 July 2012. Disponível em:

http://www.taxjustice.net/cms/upload/pdf/Inequality 120722 You dont know t he half of it.pdf Acesso em: 27.09.2012.

SCHIERMEIER, Q. IPCC: Despite hiatus, climate change here to stay. Nature/News, 27 September 2013.

SCHULMEISTER, S. Implementation of a General Financial Transactions Tax. ÖSTERREICHISCHES INSTITUT FÜR WIRTSCHAFTSFORSCHUNG, June 2011.

Disponível em:

http://www.wifo.ac.at/wwa/downloadController/displayDbDoc.htm? item $=S 2011$ GENERAL FINANCIAL TRANSACTIONS TAX 41992\$.PDF Acesso em: 06.10.2012.

SCHUMPETER, J. Capitalismo, Socialismo e Democracia. Rio de Janeiro: Zahar, 1961.

SHIVA, V. Resourses. In: SACHS, W. (ed.) The Development Dictionary. A Guide to Knowledge as Power. London: Zed Books, 1992.

SINCLAIR, T. J. Beyond international relations theory: Robert W. Cox and approaches to world order. In: COX, R. with SINCLAIR, T. Approaches to world order. Cambridge: Cambridge University Press, 1996.

SPENGLER, O. A Decadência do Ocidente. Esboço de uma morfologia da História Universal. Rio de Janeiro: Zahar Editores, 1978.

2013.

SPINELLI, B. Il giudizio universale di JP Morgan. Repubblica, 26 giugno em : http://www.repubblica.it/politica/2013/06/26/news/il giudizio universale di jpmorgan-61862080/ Acesso em 26.06.2013.

STIGLITZ, J. A crisis of confidence. The Guardian, 22 october 2008. Disponível em: http://www.theguardian.com/commentisfree/cifamerica/2008/oct/22/economyfinancial-crisis-regulation Acesso em 28.11.2013.

UNEP. Green Economy Developing Countries Success Stories. United Nations Environment Programme. 2010. Disponível em: http://www.unep.org/pdf/greeneconomy successstories.pdf Acesso em: 01.02.2012.

UNEP. Decoupling Natural Resource Use and Environmental Impacts from Economic Growth. United Nations Environment Programme. Disponível em: 
http://www.unep.org/resourcepanel/decoupling/files/pdf/Decoupling Report Engl ish.pdf Acesso em: 03.04.2012. 